\title{
Validation of Serious Games Attributes Using the Technology Acceptance Model
}

\author{
Amri Yusoff, Richard Crowder and Lester Gilbert \\ University of Southampton \\ Southampton, United Kingdom \\ \{ay06r, rmc, lg3\} @ecs.soton.ac.uk
}

\begin{abstract}
The paper introduces a conceptual model for the design of serious games and uses the Technology Acceptance Model (TAM) for its validation. A specially developed game introduced international students to public transport in Southampton. After completing the game, participants completed a short questionnaire and the data was analysed using structural equation modelling (SEM). The results identified the attributes and combinations of attributes that led the learner to accept and to use the serious game for learning. These findings are relevant in helping game designers and educational practitioners design serious games for effective learning.
\end{abstract}

Keywords: Technology Acceptance Model; Serious games; framework; model; Attributes, Acceptance

\section{INTRODUCTION}

One of the current challenges in education is to develop improved and more effective teaching methods. Shadbolt [1] noted that in the near future, a significant proportion of education will utilise game technologies as part of the learning experience. One of the given reasons is that this approach can attract a wide range of learners to "play" and keep them engaged until they have achieved the learning objectives.

In addition, the current generation of learners has grown up in a digital environment and are surrounded by modern technologies such as computers and mobile phones. They are playing more games on computers, or on games devices, compared with previous generations. It is apparent that the delivery and organization of teaching material needs to be changed to accommodate young learners and to meet their expectations [2]. Providing these learners with suitable games could be one of the solutions for meeting these needs, together with the support of traditional teaching in the classroom.

Many companies, researchers and educationists are developing serious games for learning [3], for example, the U.S. Army has developed ALTSIM (Advanced Leadership Training Simulation), where the trainee is presented with a virtual environment of a tactical command center [3]. With the use of realistic characters and events, trainees are trained to give a correct response based on the decision made using information from the virtual environment.

However, due to unclear standards and guidelines, it is difficult to claim that these games really meet the learner's requirements or expectations. There are also numbers of games being developed for educational purposes but the games are too easy for their level or just too difficult [4]. It could be that most of the available games for learning have not been created by pedagogy experts [4].

In order to address these problems, this research will take two approaches to the consideration of serious games. First, we will define a model for serious games based on learning theory that will result in effective learning. Secondly, we will use the Technology Acceptance Model (TAM) to evaluate our model.

In this paper we define a serious game as a learning tool that incorporates game technology for the purpose of achieving learning objectives other than for pure entertainment.

\section{SERIOUS GAMES FRAMEWORK}

The framework that we have developed includes learning and pedagogy theory in combination with gaming requirements [5-8] and aims to establish a conceptual model that will be used by the game designer or educational practitioner when designing serious games for effective learning. The framework is illustrated in Figure 1 and is an evolution of the input-process-outcome game model discussed by Garris et al [5] and presented by Yusoff et al [9]. The individual components of the model are discussed in this section.

\section{1) Capability}

Capability refers to the cognitive, psychomotor, and possibly affective skills which the learner is to develop as a result of playing the game. These skills have been identified by, for example, Bloom [10] in the cognitive domain, Dave [11] in the psychomotor domain, and Krathwohl [12] in the affective domain.

2) Instructional content

The instructional content is the subject matter that it is intended that the learner should learn. The detail of the actual subject matter to learn, or the type of content that the learner learns, could be an exhaustive list. Gilbert \& Gale [7] illustrate the classification of content into four types: facts, procedures, concepts, and principles. 


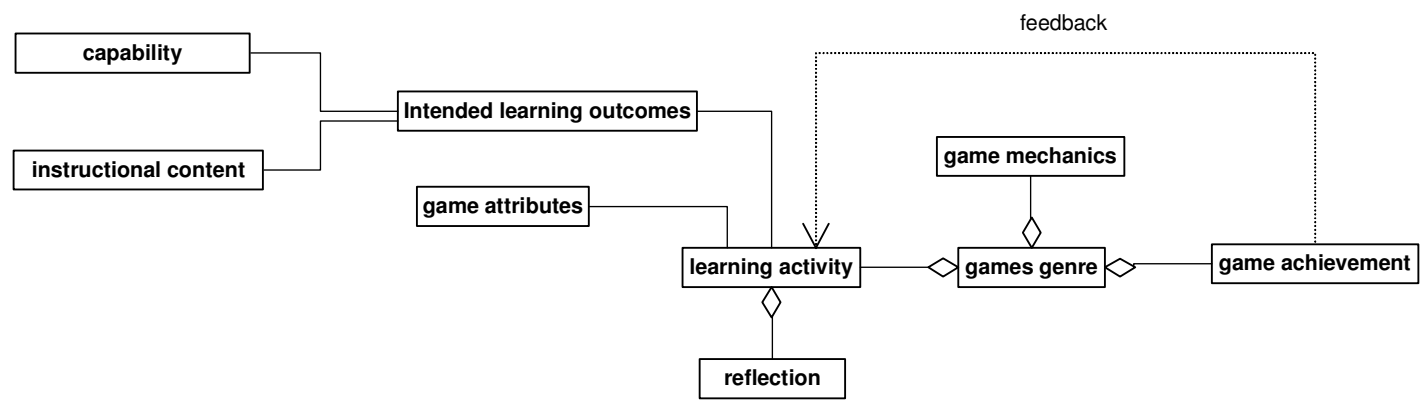

Figure 1 Conceptual Framework for Serious Games shown as a Structural Class diagram [9]

\section{3) Intended learning outcomes}

Learning outcomes are the goals to be achieved from playing the serious game. An intended learning outcome is a particular combination of capability and subject matter. For example, the learner should be able to recall the date of the battle of Hastings or should be able to analyse whether a particular bird is a raptor.

Typical examples of learning outcomes are based on taxonomies of educational objectives with learner capabilities drawn from the psychomotor, cognitive, and affective domains [7]. For example, pilots undertake rigorous training in both the classroom and in aircraft. A study has shown that by introducing a number of hours playing aviation computer games, pilots have performed better in test flights [13].

\section{4) Serious Game attributes}

Game attributes are those aspects of a game which support learning and engagement and were identified from a literature review of behaviourist, cognitive, constructivist, educationist, and neuroscience perspectives [9], as listed in Table 1.

\section{5) Learning activity}

Learning activity is the activity designed to keep the learner engaged and learning in the game world. The deep involvement or immersion by the learner depends on the effective design of these activities.

Gilbert \& Gale [7] suggested a number of methods for constructing learning activities to support given intended learning outcomes. For example, if a learner needs to be able to recall a concept, the learning activities would include showing an example of the concept and asking the learner for the concept name, followed by feedback on the answer.

Activities should involve learning materials that are appropriate and challenging for the target learner seeking competency at a level slightly above that of their current competency [14]. The majority of game designers spend considerable time in perfecting this area of "game play" in order to make the game successful.

\section{6) Reflection}

Reflection is where the learner thinks about the purpose of the learning activities that have been undertaken, and decides the strategy to apply during the next activity.
Reflection should take place within the game without letting the learner step out of the game world, and this can be done by offering reflection activities within the game. Garris et al [5] have stated that the reflection activity can be included within the game by providing a description, an explanation of why this activity is chosen, a discussion of the errors made by the learner, and some corrective suggestions.

\section{7) Games genre}

Game genre is the type or category of the game played. Genres range from "beat-em-ups", through open-world sandboxes, to strategy games, and simulation. More recently game designers have developed serious games adopted for learning purposes according to games genres.

\section{8) Game mechanics}

Game mechanics and game rules define the details of the game [6]. If the game genre is a Real Time Strategy (RTS), for example, then it may require game mechanics of resource management and territory control. The desired learning activities and required instructional content influence the selected game mechanics in order to design a better game that will suit a particular style of learning, a particular target learner, or a particular set of intended outcomes.

\section{9) Game achievement}

Game achievement is the level of learner achievement in playing these games. This achievement can be indicated by the game scores, total amount of resources or assets collected within the game, or time taken to achieve game goals. In addition, it gives the pleasure of reward to the learner, and also serves a purpose of learner assessment. The learning activities can be modified based on the student's achievements and progress in the game.

This paper demonstrates that the proposed conceptual framework for serious games supports the design of serious games for effective learning, and to confirm that serious games, based on the proposed framework, would be both accepted by the learner and would be useful for learning. It is believed that these issues can be answered by using the Technology Acceptance Model applied to serious games.

\section{TECHNOLOGY ACCEPTANCE MODEL.}

The Technology Acceptance Model (TAM) [15] has been used in information technology to predict the user acceptance of new technology, and has been applied to 
applications such as email [16], multimedia learning [17], World Wide Web [18, 19] and e-courseware [20]. We employed Venkatesh's revision of the TAM model [21] in this paper. There is no research known to us that considers the acceptance of serious games from the learner's viewpoint by using the Technology Acceptance Model.

We wish to demonstrate that the proposed framework is effective for learning, and to confirm that serious games, based on the proposed framework, would be both accepted by the learner and would be useful for learning. We believe these issues can be answered by using the Technology Acceptance Model applied to serious games.

The highlighted serious games attributes in Table 1 identifies four of the attributes (transfer of learnt skills, learner control, reward, and situated learning) selected as the most important in their association with the TAM model. Figure 2 shows the resulting TAM model in the SEM format.

TABLE 1 THE SELECTED SERIOUS GAMES ATTRIBUTES WITH THEIR MOST IMPORTANT ASSOCIATION WITH TECHNOLOGY ACCEPTANCE MODEL

\begin{tabular}{|c|c|c|}
\hline $\begin{array}{l}\text { Attributes for } \\
\text { Serious Games }\end{array}$ & Values for Learning and Education & $\begin{array}{c}\text { Association with TAM from the learner's } \\
\text { viewpoint }\end{array}$ \\
\hline Incremental learning & $\begin{array}{l}\text { Learning material is delivered incrementally. } \\
\text { Additional new knowledge is delivered and not } \\
\text { done all at once. It will have a proper start and end } \\
\text { section. Learner feels and learns in a natural way } \\
\text { and less complex. }\end{array}$ & $\begin{array}{l}\text { Incremental learning is seen as a normal way of } \\
\text { learning. This attribute would not be a factor for } \\
\text { the learner to use or reject this technology. }\end{array}$ \\
\hline Linearity & $\begin{array}{l}\text { Learning will be in sequence. This will suit the } \\
\text { sequential learner. However, due to the games } \\
\text { flexibility, active learner can skip chapters. }\end{array}$ & $\begin{array}{l}\text { Linear also appears to be a natural flow of } \\
\text { learning and there is no strong connection for } \\
\text { urging the user to choose a serious game for } \\
\text { learning. }\end{array}$ \\
\hline Attention span & $\begin{array}{l}\text { This concerns with the cognitive processing and } \\
\text { short-term memory loads placed upon the learner } \\
\text { by the game. These loads need to be carefully } \\
\text { calibrated to the target learner Not to be } \\
\text { overwhelmed and too long in the learning process. }\end{array}$ & $\begin{array}{l}\text { There is probably a weak link between learner } \\
\text { needs and playing the serious games. }\end{array}$ \\
\hline Scaffolding & Support and help during learning within the games. & $\begin{array}{l}\text { Learner may assume that every game always } \\
\text { come with help, support tips or hints in the form } \\
\text { of a game manual or online help. }\end{array}$ \\
\hline $\begin{array}{l}\text { Transfer of learnt } \\
\text { skills }\end{array}$ & $\begin{array}{l}\text { Learnt knowledge to apply to other skills in the } \\
\text { next level. }\end{array}$ & $\begin{array}{l}\text { Yes, learner would see this as a very useful thing } \\
\text { because the knowledge acquired from games can } \\
\text { be applied to different areas or other domains. }\end{array}$ \\
\hline Interaction & Higher engagement, higher learning. & $\begin{array}{l}\text { Learner may think interaction is common in } \\
\text { learning since every basic learning transaction } \\
\text { should have an interaction (two ways of } \\
\text { communication). }\end{array}$ \\
\hline Learner control & $\begin{array}{l}\text { Active learning, self study and self exploration } \\
\text { based on individual pace and experience. }\end{array}$ & $\begin{array}{l}\text { Yes, learner may view this as useful because it } \\
\text { gives a degree of freedom for the learner to learn } \\
\text { at his own pace and likes the idea of all learning } \\
\text { happening under his control. }\end{array}$ \\
\hline Practice and drill & $\begin{array}{l}\text { Repeating for harder task, better knowledge } \\
\text { retention and can have plenty of game activities for } \\
\text { drills. }\end{array}$ & $\begin{array}{l}\text { Learner may think that this is common way of } \\
\text { learning. }\end{array}$ \\
\hline $\begin{array}{l}\text { Intermittent } \\
\text { feedback }\end{array}$ & $\begin{array}{l}\text { Learner to reflect on what has been achieved so far } \\
\text { and motivated for higher score (higher learning). } \\
\text { Also using just in time feedback for learning. }\end{array}$ & $\begin{array}{l}\text { Learner thinks that every learning always has } \\
\text { feedbacks and this is normal. }\end{array}$ \\
\hline Reward & $\begin{array}{l}\text { Encourage learner and keep motivated. Negative } \\
\text { reward as punishment within the game may also } \\
\text { contribute to learning. }\end{array}$ & $\begin{array}{l}\text { Yes, learner may feel this is important to keep } \\
\text { him motivated and to keep on going. It would } \\
\text { elevate his sense of confidence and self } \\
\text { assurance in learning. }\end{array}$ \\
\hline $\begin{array}{l}\text { Situated and } \\
\text { authentic learning }\end{array}$ & $\begin{array}{l}\text { Learning where the learner can relate what is being } \\
\text { learnt within the game to the outside world. }\end{array}$ & $\begin{array}{l}\text { Yes, learner feels this is useful and can relate to } \\
\text { what is being learnt would make the learning } \\
\text { process to become easier. }\end{array}$ \\
\hline $\begin{array}{l}\text { Accommodating the } \\
\text { learner's styles }\end{array}$ & To suit and to reach out to different learner styles. & $\begin{array}{l}\text { This may be a strong factor for learner to use } \\
\text { this technology but it is quite difficult to test. } \\
\text { The result could be biased if the system happens } \\
\text { not to be suited to his learning style but } \\
\text { applicable to another group. }\end{array}$ \\
\hline
\end{tabular}




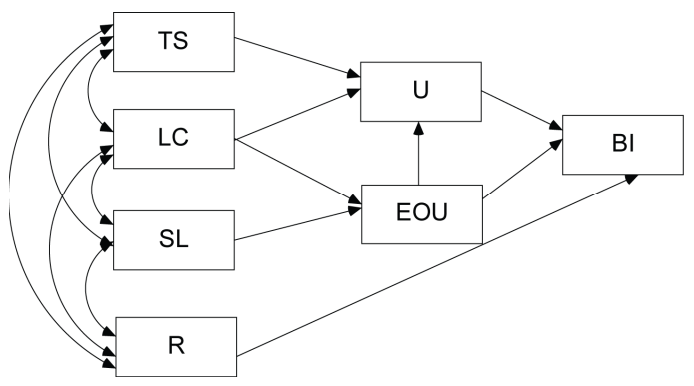

Figure 2 Proposed TAM model for Serious Games

Transfer of Learnt Skills (TS) means applying previously acquired skills to other learning. This can be done within the game by continuing to the next level. Whatever skills have been acquired can then be used in the next level to acquire new skills. The previous knowledge should be revisited and new knowledge should be gradually added to what had been previously learned. New knowledge should be constructed from previous experience.

Learner Control (LC) means that learners like to explore on their own and pick up skills (experience) within the game at their own pace.

Situated and authentic learning (SL) places the learner in an authentic environment, where they would be able to develop mental models of their experience and relate it to real life. Use of a familiar background or common examples in a game's content, and relevant to the learner's experience, should be perceived as easy to use when learning with serious games, because the learner is learning within a familiar territory.

Reward ( $\mathrm{R}$ ) comprises incentives in the game which are used to encourage the learner and to keep their motivation high.

Ease of Use (EOU) refers to a person's perception that using a serious game for learning will require minimal effort. It has been shown that users will interact with the technology if they feel that little effort is needed for using this technology in order to accomplish their tasks.

Usefulness (U) refers to the user's perception that the use of the technology could enhance their performance. The input to Usefulness also comes from ease of use, because the user would be inclined to choose tools that require minimal effort in order to solve the problem. Both perceived usefulness and ease of use are important factors that influence the user to actually use or select this technology (behavioral intention to use).

Behavioral Intention to use (BI) is the intention to perform actual behavior by the learner influenced or caused by both preceding factors of Usefulness and Ease of Use. Learners would intend to use serious games for learning in the future.

\section{THE STUDY METHODOLGY}

The study involved three steps; (i) the development of a short serious game tailored to the participants that would be used in the study, (ii) the development and delivery of a questionnaire and (iii) the subsequent analysis.

\section{A. The "Unilink" serious game}

It is recognised that many existing or off-the-shelf games could be used to undertake a study into serious games. However, we would not be confident that they would be completely compliant with the framework that we have developed. For this reason we developed the "Unilink" Bus serious game in order to fully meet the requirement of our serious games framework.

The game was developed to permit international students who were unfamiliar with the University of Southampton's bus system and to help them maximise the benefit of this method of transport

The key features of the developed game are to:.

- Recognise the location of the final destination.

- Identify the bus routes.

- Identify the bus number.

- Identify the bus stops and Interchange for bus transfer.

- Recognize where to get off the bus.

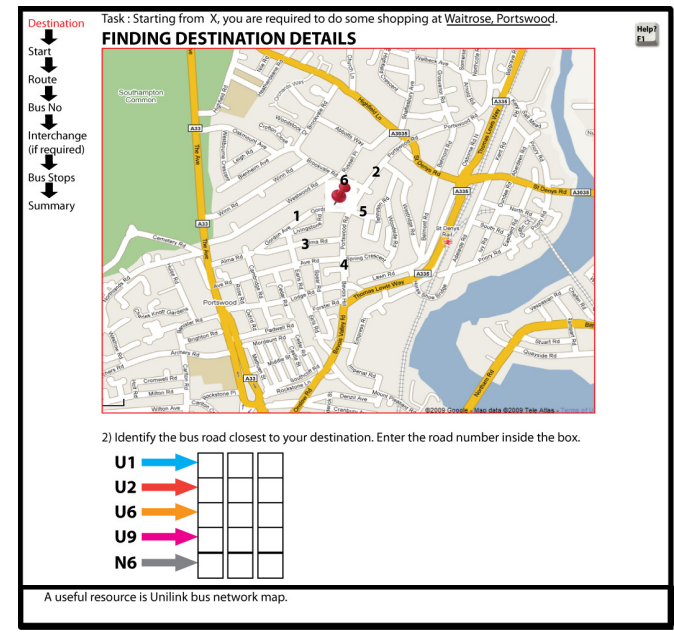

Figure 3 A screen shot from Unilink bus serious game

After the Unilink bus serious game had been initially produced, it was submitted for expert review. There were five panellists that evaluated this game ranging from game interface, gamer interaction, aesthetic design, game functionality and game progression. Then, after the game rectification, the study protocol was submitted for ethical review. 
A pilot test was done prior to the actual game survey in order to reveal and correct any problems raised before the actual run.

\section{B. Questionaires}

A questionnaire was developed to discover how the participants rated the Transfer of Learnt skills (TS), Learner Control (LC), Situated Learning (SL), Reward (R), Usefulness (U), Ease of Use (EOU) and Behavioral Intention to use (BI) with regard to the Unilink bus serious game. Each of these seven variables were assessed by four individual questions, where each response used a 5-point Likert-type scale, with "fully disagree" at the lowest and "fully agree" at the highest scale. The questions were constructed as follows

- Transfer of Learnt skills (TS) is where participants were asked whether they can use and apply the skill learned within the game to the real world (e.g., "I feel that I can use my new skills in identifying Unilink bus routes").

- Learner Control $(L C)$ is what the participants feel inside the game, whether they felt in total control of the game activity or allowed to manipulate the game activity (e.g., "This game allows me to search for the answers at my own speed").

- Situated Learning (SL) involves the provision of a gaming environment or world where the participants can relate their learning to their needs and interests in the outside world (e.g., "I can learn better if I can relate the experiences within a serious game to my experiences in real life").

- Reward $(R)$ is the arrangement in the Unilink bus serious game to encourage the participants and to keep their motivation high (e.g., "I feel encouraged to learn more about the Unilink Bus Game when it displays congratulatory messages").

- Usefulness $(U)$ refers to the participants' belief that by using this game, it could help them better in planning to ride the Unilink bus (e.g., "This Unilink Bus Game will help me use the Unilink bus service better").

- Ease of Use (EOU) is where participants feel that a minimal effort is required to learn the Unilink Bus serious game (e.g., "I find it easy to use the Unilink Bus Game because I am familiar with the operation of buttons and mouse").

- Behavioral Intention to use (BI) is the participants intention to use the Unilink Bus serious game (e.g., "If I am given a serious game of this type, I intend to use it") to help them to perform the actual task.

\section{Survey Process}

Prior to undertaking the survey a brief presentation was given to the participants informing them about the underlying research and the serious games. Then, students were invited to participate voluntarily with the Unilink bus serious game, which took 20 minutes to complete, followed by a short questionnaire. The survey was undertaken at University of Southampton between June until August 2009.

\section{Participants}

The game participants were mostly new students at the University of Southampton attending the pre-sessional courses in June 2009. These courses were designed to improve English skills for international students enrolled as undergraduates and postgraduates as part of the university entry requirements.

A total of 56 out of 200 possible participants completed both the game and the questionnaires. The group consisted of three (5.4\%) UK students and $53(94.6 \%)$ international students, of which 23 were $(41.1 \%)$ female and 33 were $(58.9 \%)$ male.

\section{E. Statistical Analysis}

The TAM serious games model in Figure 2 was analyzed with AMOS [22] by testing its relationship using Structural Equation Modeling (SEM). The detailed analysis identified a number of statistically significant paths within the model; as shown in Figure 4.

- $\quad \mathrm{R}$ and TS were strongly inter correlated

- LC and SL were strongly inter correlated

- $\quad \mathrm{TS}$ to $\mathrm{U}$

- $\quad \mathrm{LC}$ to $\mathrm{U}$

- $\quad$ SL to EOU

- $\quad$ EOU to U to BI

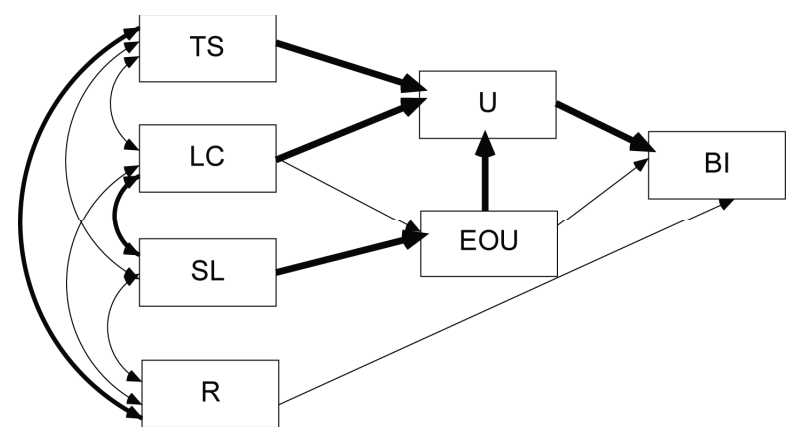

Figure 4: The TAM showing the statistically significant paths. 


\section{DISCUSSION}

The SEM analysis allowed the identification of attributes or combinations of attributes that lead a learner to use this type of game for learning.

\section{A. $\quad R$ and TS are strongly inter correlated}

Figure 4 shows that Reward and Transfer of Learnt Skills have a strong correlation link. Transfer of skill seemed to be rewarding, and reward supported Transfer of skills. The SEM results showed that reward was not significantly linked to Behavioral Intention, and so the probable path for the effects of Reward (R) upon Behavioral Intention (BI) was actually "working through" Transfer of skills (TS).

\section{B. LC and SL are strongly intercorrelated}

The result shows that learner control and situated learning are strongly correlated. This suggests that learner control supports situated learning, and situated learning is associated with perceived learner control.

\section{TS to $U$}

A high rating of Transfer of Learnt Skills (TS) leads to high perceived Usefulness (U). This result suggests learners find this serious game is useful partially because they could apply previous acquired skills to their learning and could add new knowledge to what had been most recently learned.

\section{LC to $U$}

A high rating of Learner Control (LC) leads to high perceived Usefulness (U). This result suggests learners find the game useful partially because it allowed self exploration and active learning inside the game.

\section{E. SL to EOU}

A high rating of Situated Learning (SL) leads to a high perceived Ease of Use (EOU). This suggests that learners felt that the mental models of their experience lead to minimal effort in the game. The SEM results showed that learner control was not significantly linked to ease of use, contrary to the expectation of the TAM model.

\section{F. EOU to $U$ to $B I$}

The result shows that Learner intention to use the game (BI) is not significantly linked to the game's ease of use (EOU). Instead, the result shows that EOU is significantly linked to Usefulness (U), and that it is Usefulness which is significantly linked to Behavioral intention to Use (BI.

The significant paths to Usefulness (U) were from Transfer of Skills (TS), Learner Control (LC), and Ease of Use (EOU). Usefulness (U) was the only significant link to Behavioral intention to Use (BI), strongly suggesting that learners must perceive that the serious game is useful before they would want or intent to use it.

Finally, all of the TAM components and all of the identified serious game attributes showed significant linkages and inter-correlations, and were all relevant to Behavioral intention to Use.

These findings suggest that serious game design should encompass all these attributes, while development should carefully consider the exact links between game attributes and the resulting Behavioral intention to use.

\section{CONCLUSIONS}

In this paper we have demonstrated the use of the Technology Acceptance Model to validate a number of attributes used in the design and development of a serious game. Following identification of the attributes these were mapped on to a modified form of the TAM. In order to evaluate the model a serious game was developed, and together with a supporting questionnaire was administered to over 50 participants.

An analysis of the data using SEM allows us to draw a number of interim conclusions.

Firstly the approach we have proposed is effective and lightweight and had resulted in an acceptable analysis of the TAM for a serious game application.

The results allow us to predict the learner intention to use the serious game. The combination of Transfer of Learnt Skills (TS) to Usefulness (U), Situated Learning (SL) to Ease of Use (EOU), Learner Control (LC) to Usefulness (U) and Ease of Use (EOU) to Usefulness (U) to for Behavioral Intention to use (BI) provide an indication of how to design successful and effective serious games that would ensure learners use them for learning. Educational practitioners also would find this helpful in evaluating games for learning purposes. The results both identified the critical predictors of Behavioral intention to use and validated the serious games framework.

\section{ACKNOWLEDGMENT}

The authors acknowledge the financial support from the Universiti Pendidikan Sultan Idris.

\section{REFERENCES}

[1] N. Shadbolt, "Ufi skills evolution report 2008," in A vision: the future of workplace skills.: Retrieved November 28, 2008, from http://www.ufi.com/skillsevolution/FINAL\%20VERSION_Skills\%20 Evolution\%20Report.pdf.

[2] T. C. Reeves, "Do Generational Differences Matter in Instructional Design?.". vol. 2009: University of Georgia, 2008.

[3] N. Iuppa and T. Borst, "Case studies.," in Story and Simulations for Serious Games : Tales from the Trenches, C. Anderson, Ed. Oxford: Focal Press, 2007, pp. 1-23.

[4] D. R. Verdugo and I. A. Belmonte, "Using Digital Stories to Improve Listening Comprehension with Spanish Young Learners of English," Language Learning \& Technology, vol. 11, pp. 87-101, 2007.

[5] R. Garris, R. Ahlers, and J. E. Driskell, "Games, motivation, and learning: A research and practice model," Simulation \& Gaming, vol. 33, pp. 441-467, 2002. 
[6] J. Thompson, B. Berbank-Green, and N. Cusworth, The computer game design course : principles, practices and techniques for the aspiring game designer. London: Thames \& Hudson, 2007.

[7] L. Gilbert and V. Gale, Principle of E-Learning Systems Engineering. Oxford: Chandos Publishing, 2008.

[8] M. Prensky, "Why and how it works.," in Digital Game-Based Learning New York: McGraw-Hill, 2001, pp. 145-163.

[9] A. Yusoff, R. Crowder, L. Gilbert, and G. Wills, "A Conceptual Framework for Serious Games," in The 9th IEEE International Conference on Advanced Learning Technologies (ICALT 2009), Riga, Latvia, 2009.

[10] D. R. Clark, "Instructional system design concept map," Retrieved November 13, 2009 from http://nwlink.com/ donclark/hrd/ahold/isd.html, 2004.

[11] D. Kennedy, Á. Hyland, and N. Ryan, "Writing and using learning outcomes: A practical guide.." vol. 2009: University College Cork, 2007

[12] D. R. Krathwohl, "A revision of bloom's taxonomy: An overview," Theory into practice, vol. 41, 2002.

[13] C. A. Connolly, J. Johnson, and C. Lexa, "AVATAR: An intelligent air traffic control simulator and trainer," LNCS, vol. 2363/2002, pp. 496-506, 2007

[14] J. P. Gee, "Learning and identity.," in What Video Games Have to Teach Us About Learning and Literacy New York: Palgrave Macmillan, 2007, pp. 65-69.

[15] F. D. Davis, "Perceived usefulness, perceived ease of use and user acceptance of information Technology," MIS Quarterly, vol. 13, pp. 318-339, 1989.

[16] D. Gefen and D. W. Straub, "Gender differences in perception and use of e-mail : An extension to the technology acceptance model," MIS Quarterly, vol. 21, pp. 389-400, 1997.

[17] R. G. Saade, F. Nebebe, and W. Tan, "Viability of the 'Technology Acceptance Model' in multimedia learning environments : A comparative study.," in Interdisciplinary Journal of knowledge and learning objects. vol. 2009, 2007.

[18] A. L. Lederer, D. J. Maupin, M. P. Sena, and Y. Zhuang, "The technology acceptance model and the world wide web," Decision support systems, vol. 29, pp. 269-282, 2000.

[19] R. Agarwa and E. Karahanna, "Time flies when you're having fun: Cognitive absorbtion and beliefs about technology usage," MIS Quarterly, vol. 24, pp. 665-694, 2000.

[20] N. Park, K. M. Lee, and P. H. Cheong, "University instructors' acceptance of electronic courseware : An application of the technology acceptance model," Journal of Computer-Mediated Communication, vol. 13, 2007

[21] V. Venkatesh and F. D. Davis, "A Theoretical Extension of the Technology Acceptance Model: Four Longitudinal Field Studies," Management Science, vol. 46, pp. 186-204, 2000.

[22] AMOS, "Structural equation modeling to test relationships," Retrieved November 14, 2009 from http://www.spss.com/amos/, 2009. 